\title{
A Progressão Continuada no estado de São Paulo: considerações a partir da perspectiva de educadores
}

\author{
Progressão Continuada em São Paulo
}

\author{
Lygia de Sousa Viégas \\ Marilene Proença Rebello de Souza
}

Resumo

Este estudo analisou a Progressão Continuada na perspectiva de educadores do ensino fundamental. O método utilizado foi a realização de redações e grupos de reflexão visando conhecer como os educadores compreendem a política educacional, como a progressão acontece na sala de aula e quais dificuldades são enfrentadas na sua implantação. $O$ consenso entre docentes e discurso oficial reside na necessidade de enfrentar os altos índices de reprovação e evasão existentes na escola pública. A dissensão entre professores e o projeto governamental encontra-se principalmente na maneira como tem sido implementado pois há pouca participação dos educadores no processo. Há uma concepção negativa em relação à capacidade de aprendizagem do aluno das camadas populares tanto no discurso oficial quanto na visão docente. Considera-se que a distância entre a intenção da proposta governamental e a realidade de sua implementação pode comprometer a democratização e a qualidade de ensino.

Palavras-chave: Ensino básico; Política pública; Progressão Continuada.

\section{The Continued Progression in the state of São Paulo: considerations based on the educators point of view}

\begin{abstract}
:
This study analyzed the Continued Progression in the perspective of the educators in the elementary school. The method used was the production of texts and organization in groups of reflexion aiming to know how the educators understand educational politics, how the progression took place in the classes and which are the dificulties faced in its implantation. The consence between teachers and the official speech is in the necessity of facing the high index of failling and school evasion in the Public system. The divergence between teachers and the governamental policy is,specially, in the manner of how it has been implemented, because there is not enough participation of the teachers in the process. There is a negative conception about the learning skill of the students coming from families with low economic condition as much in the official speech as in the teachers' point of view. The distance between the intention of the governamental policy and the reality of its implementation is considered to endanger the democratization and the teaching's quality. Keywords: Elementary school; public policy; Continued Progression
\end{abstract}

\section{La Progresión Continuada en el estado de São Paulo: consideraciones a partir de la perspectiva de educadores}

\section{Resumen}

Este estudio analizou la Progresión Continuada en la perspectiva de educadores de la enseñanza fundamental. El método empleado consistió en la realización de redacciones y grupos de reflexión objetivando conocer como los educadores comprenden la política educacional, como la progresión 
acontece en la sala de aula y cuales dificultades son enfrentadas en la su implantación. El consenso entre docentes y discurso oficial reside en la necesidad de enfrentamiento de los altos índices de reprobación y evasión existentes en la escuela pública. La disensión entre profesores y el proyecto del gobierno se encuentra principalmente en la manera como viene siendo implementado, con poca participación de los educadores en el proceso. Hay una concepción negativa en relación a la capacidad de aprendizaje del alumnado de las camadas populares, tanto en el discurso oficial como en la visión docente. Desde nuestro punto de vista, la distancia entre la intención de la propuesta del gobierno y la realidad de su implementación coloca en riesgo la finalidad de esta política pública educacional relativa a la democratización y a la mejoría de la calidad de la enseñanza.

Palabras-clave: Enseñanza básica; Política pública; Progresión Continuada.

\section{Introdução}

O tema do acesso/permanência/qualidade do ensino brasileiro tem sido abordado criticamente por diversos autores da Educação. Especialmente a partir da década de 1980, destacaram-se Beisiegel (198I), Saviani (1986) e Ferraro (1999).

Ferrari (1985), ao analisar cem anos de dados educacionais brasileiros (1885-1985), chamou a atenção para o fato de que aproximadamente $2 / 3$ das crianças reprovavam ou evadiam da escola. Para ele, em todos os casos, trata-se de exclusão escolar (desdobrada em exclusão da escola e na escola). Isso significa que, se por um lado, a falta de vagas nas escolas brasileiras não é problema superado, por outro, estar no interior da escola não pode ser entendido como inclusão, uma vez que, além de freqüentá-la, o aluno deve beneficiar-se da escolarização, aprender.

No início dos anos 90, índices oficiais denunciavam que a ampliação do acesso e permanência nas escolas paulistas ocorreu sem que alunos ultrapassassem as séries iniciais, cuja principal causa residia nas retenções. Esta realidade refletia-se, dentre outros âmbitos, na defasagem série/idade, que chegou a atingir $30 \%$ dos alunos de $\mathrm{I}^{\mathrm{a}}$ a $4^{\mathrm{a}}$ séries, e $40 \%$ entre alunos de $5^{\mathrm{a}}$ a $8^{\mathrm{a}}$ séries (São Paulo, 1996), incidindo principalmente sobre alunos provenientes de regiões mais pobres ou periféricas.

A defasagem série/idade foi caracterizada como estágio anterior à outra realidade alarmante: a evasão (exclusão da escola). De fato, estatísticas nacionais apontam que a evasão não ocorre precocemente, mas é, ao contrário, fruto de anos de tentativas frustradas de escolarização - o aluno 'abandona' a escola, em média, após cinco anos; os poucos que concluem os oito anos do ensino fundamental, fazem-no após uma média de II,2 anos de escolarização (Brasil, 1996). A evasão seria, portanto, produto de um processo de expulsão (Ribeiro, 1991).

Por esses motivos, o processo de exclusão na escola tem aparecido nas discussões de educadores, pais e pesquisadores bem como se constituído em um dos principais desafios de gestores da educação pública brasileira.

No campo das políticas públicas, o governo do estado de São Paulo implementou, nas últimas décadas, projetos cujo mote é a diminuição da repetência, da defasagem série/idade e da evasão. Dentre os projetos, destaca-se a Progressão Continuada, implantada em todas as escolas públicas desse estado em 1998, reorganizando o ensino fundamental em dois ciclos de quatro anos cada (Ciclo I: I à 4a; Ciclo II: $5^{\mathrm{a}}$ à $8^{\mathrm{a}}$ ), nos quais os alunos não podem ser retidos, à exceção dos faltosos.

\section{Caminhando na construção da Progressão Continuada}

Ao analisar a Progressão Continuada, é preciso entender sua elaboração e implantação como resultado de um conjunto de ações do Poder Público na direção de contornar os índices de reprovação e evasão no sistema de ensino paulista. $O$ enfrentamento da repetência pode ser observado em discursos do início do século $X X$ no Brasil. Ao menos, desde a Primeira República, há a defesa da então chamada 'promoção automática' (Sampaio Dória, 1918), proposta que é retomada na década de 50 , sobretudo por Almeida Júnior (1957), Juscelino Kubitschek (1957) e Dante Moreira Leite (1959/1999). Afora a defesa no plano das idéias, houve a primeira implantação efetiva no estado de São Paulo em 1968, com a Reforma do Ensino Primário (SÃO PAULO, 1969). 
Em 1984, a instituição do Ciclo Básico foi um Importante passo nessa direção, ou seja, no contexto de retomada do processo democrático'. Implantada em todas as escolas da rede estadual paulista, por meio de um decreto-lei, tal política apresentava-se como alternativa contra os altos índices de repetência localizados na passagem para a $2^{\mathrm{a}}$ série. Assim, as duas séries iniciais passaram a compor um ciclo a ser concluído em dois anos. Seus idealizadores acreditavam que a ruptura da lógica das seriações viabilizaria a continuidade do processo educativo de maneira "mais flexível", garantindo aos alunos "mais tempo para aprender". Nesse momento, fazia-se presente o argumento da relevância social da não-reprovação, recuperando - caráter político da educação ao enfatizar a escolarização enquanto direito.

O documento deixa transparecer que o impasse em torno da não-reprovação não havia sido superado por educadores e gestores, na direção de um consenso, o que se nota no seguinte trecho:

“Tem-se pensado, erroneamente, que o Ciclo Básico implica a promoção automática como um recurso para se evitar que os alunos se sintam fracassados e com isso, a auto-imagem negativa dos repetentes seja diminuída, ou mesmo que a intenção seja a de manipular índices de aprovação na rede, transferindo-se para as séries subseqüentes esses problemas. Não se trata disso. Trata-se de definitivamente deixar de insistir no erro histórico de punir o aluno através de reprovação, por falhas que na verdade são da própria rede. Por isso, é preciso assumir a alfabetização e não apenas ficar à caça dos culpados pela repetência. Nesse sentido, tratase de viabilizar condições para que, respeitadas as diferenças individuais e consideradas as diferenças sociais e culturais, seja possível levar o conjunto dos alunos a atingir um patamar comum que implique o domínio efetivo de conhecimentos básicos que devem estar ao alcance de todos e não apenas de uns poucos" (1987, p. 36, grifo no original).

Após o primeiro ano de Ciclo Básico, gestores da política educacional paulista divulgaram um documento de avaliação das repercussões deste projeto nas escolas, no qual há avaliações positivas bem como críticas à proposta (Espósito, 1985). Quanto às críticas, professores questionaram a pouca participação na elaboração e implementação da proposta, culminando na inexistência de preparação que subsidiasse o trabalho nesse novo regime. Especial destaque incidiu sobre os critérios de promoção, considerados complexos, sendo necessária ampla discussão e formação docente a respeito. Apesar dessas críticas, o documento avalia, ao final que "o saldo da primeira etapa da implantação do Ciclo Básico é considerado positivo" (p. 22).

Em que dimensão o Ciclo Básico interferiu na questão da exclusão na escola que atingia alunos das séries iniciais? De maneira geral, os dados educacionais ilustram uma drástica redução dos índices de reprovação na passagem para a segunda série do ensino fundamental. Mas também revela que o estrangulamento escolar apenas deslocou-se na passagem do Ciclo Básico para a $3^{\mathrm{a}}$ série.

A intenção da Secretaria, ao implantar o Ciclo Básico, era apenas dar "início à reorganização efetiva do ensino de $1^{\circ}$ grau que deverá se estender às outras séries revendo os programas, redefinindo os conteúdos e metodologias, modificando o processo de avaliação, investindo na organização da escola" ( $p$. 10). No entanto, os ciclos restringiram-se aos dois anos iniciais do ensino fundamental até 1998, quando foram estendidos aos demais anos desse nível de ensino.

\footnotetext{
'No Brasil, após longo período de ditadura militar, desencadeou-se lentamente o processo de 'redemocratização'. Em I982, o estado de São Paulo elegeu pelo voto direto seu governador, Franco Montoro. Ao assumir o governo, a equipe gestora da Secretaria da Educação convidou todos os integrantes da rede a discutir os problemas de ensino e os rumos da educação. A discussão, que serviria de subsídio à política educacional a ser implementada, deveria centrar-se em dois eixos: participação e democratização. A idéia era que, com a democratização do país, também a escola pública seria democratizada.
} 


\section{A Progressão Continuada nos documentos oficiais de implantação}

A instituição do Regime de Progressão Continuada ocorreu na rede estadual de ensino por meio da Resolução SE, no.4, de 15 de janeiro de 1998, a qual previa a organização do ensino fundamental em dois ciclos de quatro anos, a não retenção no interior do ciclo bem como a criação de providências que evitassem a evasão escolar na defesa dos direitos da criança e do adolescente.

Sustentando tal implantação, há um parecer do Conselho Estadual de Educação (1997a) cujo argumento central focaliza os altos índices de reprovação e defasagem série/idade, apontados como incompatíveis com a democratização do ensino. Segundo afirma o parecer,

"É preciso varrer da nossa realidade a 'pedagogia da repetência' e da exclusão e instaurar definitivamente uma pedagogia da promoção humana e da inclusão. $O$ conceito de reprovação deve ser substituído pelo conceito de aprendizagem progressiva e contínua" (p. 153).

Baseando-se no artigo 32 da LDB (1996), a Progressão Continuada contribuiria para a resolução de problemas educacionais históricos: "a viabilização da universalização da educação básica, a garantia de acesso e permanência das crianças em idade própria na escola, a regularização do fluxo dos alunos no que se refere à relação idade/série e a melhoria geral da qualidade do ensino" (p. 150). Como argumento, parte-se das perspectivas educacional, psicológica e econômica, que não raro se confundem, sendo esta última a mais acentuada:

"Uma mudança dessa natureza deve trazer, sem dúvida, benefícios tanto do ponto de vista pedagógico como econômico. Por um lado, o sistema escolar deixará de contribuir para o rebaixamento da auto-estima de elevado contingente de alunos reprovados. Reprovações muitas vezes reincidentes na mesma criança ou jovem com graves conseqüências para a formação da pessoa, do trabalhador e do cidadão. Por outro lado, a eliminação da retenção escolar e decorrente redução da evasão deve representar uma sensível otimização dos recursos para um maior e melhor atendimento de toda a população. A repetência constitui um pernicioso 'ralo' por onde são desperdiçados preciosos recursos financeiros da educação. $\mathrm{O}$ custo correspondente a um ano de escolaridade de um aluno reprovado é simplesmente um dinheiro perdido. Desperdício financeiro que, sem dúvida, afeta os investimentos em educação, seja na base física (prédios, salas de aula, equipamentos), seja, principalmente, nos salários dos trabalhadores do ensino. Sem falar do custo material e psicológico por parte do próprio aluno e de sua família" (p. I5I-2, itálicos inserido).

Segundo o Conselho Estadual de Educação, esta política fundamenta-se em dois grandes eixos: flexibilidade e avaliação.

A flexibilidade estaria presente "nas amplas e ilimitadas possibilidades de organização da educação básica", assim como nos "mecanismos de classificação e reclassificação de alunos, até mesmo 'independentemente de escolarização anterior'”. Há uma mudança radical na concepção de educação pois, a partir desse momento, a referência básica de classificação do aluno passa a ser etária:

"É óbvio que outros mecanismos de avaliação do nível de competência efetiva do aluno e, se necessário, de atendimento especial para adaptação ou recuperação devem estar associados à referência básica da faixa etária. $O$ que importa realmente é que a conclusão do ensino fundamental se torne uma regra para todos os jovens aos 14 ou 15 anos de idade" (p. I53, itálicos inseridos).

Maior ênfase foi dada ao segundo eixo - a avaliação. Segundo declara, ela era, até então, "procedimento decisório quanto à aprovação ou reprovação", funcionando de forma "punitiva e excludente". Após caracterizá-la como produto de uma "perversa distorção da educação brasileira", sugere que tal concepção seja substituída pela de "progresso e desenvolvimento da aprendizagem”. 
Tal foi a importância atribuída à avaliação que uma indicação oficial tratou exclusivamente do tema, a CEE no. 22/97 (1997b). Conforme este documento, a avaliação deveria ser "instrumento-guia" para sinalizar "as heterogeneidades do desenvolvimento de habilidades e conhecimentos entre os alunos, orientando-os e aos seus professores quanto ao perfil de sua progressão pelos anos escolares". Assim, não se limitaria à aprendizagem dos alunos, incluindo, agora, a própria instituição escolar. Com isso, deixaria de ser mecanismo de corte, passando a focalizar os efeitos da ação do professor e a formação do aluno. Por fim, ela deveria valorizar "qualquer indício que revele o desenvolvimento dos alunos, sob qualquer ângulo" (p. 254).

A Progressão Continuada viria, assim, romper com "eventuais resistências ao que hoje é cientificamente comprovado: que toda criança é capaz de aprender, se lhe forem oferecidas condições de tempo e de recursos para que exercite suas competências ao interagir com o conhecimento" (p. 256, itálicos inseridos).

Embora a proposição fosse de que todos concluíssem o ensino fundamental em oito anos, o Conselho reconhece que haveria alunos que demorariam 'mais um ou dois anos' para concluí-lo. Pede atenção, no entanto, para que na passagem entre os ciclos não se instalasse "novo 'gargalo' ou ponto de exclusão", declarando, ainda, que "a extensão em anos para este percurso para número significativo de alunos, ou a evasão decorrente da não progressão, em um sistema ou em uma escola, estarão sinalizando claramente disfunções institucionais sérias a serem verificadas” (p. 255, itálicos inseridos).

Presente nos pareceres do Conselho é o reconhecimento de que se trata de uma "mudança radical e profunda", pois "em lugar de procurar os culpados da não aprendizagem nos próprios alunos, ou em suas famílias, ou nos professores, define-se uma via de solução que não seja pessoal, mas sim institucional” (1997a, p. I52). Assim, prevê uma atitude docente contrária, indicando a ausência de consenso em torno da decisão oficial:
"É importante registrar que a mudança pretendida conta com a adesão e o apoio de amplos setores da comunidade educacional. Não há que se iludir, entretanto, de que não haverá resistência sob a alegação apressada e sem fundamento de que se estará implantando a promoção automática, ou a abolição da reprovação, com conseqüente rebaixamento da qualidade de ensino" (p. 153).

Sugere, no entanto, que a resistência poderia ser evitada se fosse garantido, ainda, minimizar desconhecimentos e distorções em relação ao projeto.

Dentre as distorções, destaca-se a distinção entre Promoção Automática ("sugestiva de menor investimento no ensino") e Progressão Continuada ("mecanismo inteligente e eficaz de ajustar a realidade do fato pedagógico à realidade dos alunos"). No caso desta última, "todo esforço possível e todos os recursos disponíveis devem ser providos pela escola e pelo sistema para levar o aluno ao aproveitamento das atividades escolares para seu desenvolvimento cognitivo e social e, por conseqüência, ao progresso" (p. 254-5).

\section{A Progressão Continuada no dia-a-dia da escola}

Considerando a complexidade envolvida na construção de políticas públicas na vida escolar, aproximamo-nos de uma escola situada na capital paulista, a fim de realizar uma pesquisa de caráter qualitativo (André \& Lüdke, 1986; Ezpeleta \& Rockwell, 1986), objetivando conhecer como professores da rede pública estadual paulista compreendem tal política, que dificuldades enfrentam em sua implementação e como lidam com as mudanças no dia-a-dia escolar. Durante um semestre, convivemos com um grupo de professores participando das reuniões semanais de HTPC (Horário de Trabalho Pedagógico Coletivo). O trabalho de campo desenvolveu-se de forma intensa, com atividades que englobaram redações individuais e discussões coletivas nos denominados "grupos reflexivos"2. 
A constituição do grupo, procedimento central na pesquisa, deu-se a partir do contato com os professores, ou seja, foi fruto da relação estabelecida entre pesquisadora, grupo pesquisado e tema de pesquisa, sendo construído coletivamente. Participaram do grupo em torno de oito docentes pertencentes ao Ciclo II (de $5^{\mathrm{a}}$ até $8^{\mathrm{a}}$ Séries) e Ensino Médio, juntamente com a coordenadora pedagógica.

Iniciamos a aproximação com os professores, solicitando que escrevessem uma redação sobre a Progressão Continuada ${ }^{3}$. As redações focalizavam o entendimento acerca desta política educacional, a prática em sala de aula e considerações sobre o trabalho docente. No contexto de sua realização, os professores constantemente conversavam sobre 0 tema, quando acentuavam a falta de espaços coletivos de debate em torno dessa questão.

Ao analisarmos as redações, verificamos o forte tom de desabafo e angústia dos professores, observado no momento mesmo de sua realização. Seu conteúdo ainda revelava um desconhecimento do discurso oficial bem como manifestava o sentimento de isolamento no trabalho docente no contexto de implantação desta política.

Considerando essas constatações, propôs-se aos professores um espaço grupal que pudesse pôr em comum suas expectativas e dúvidas com relação à Progressão Continuada. As discussões focalizaram a leitura coletiva do Parecer CEE-08/1997 e de documentos trazidos pelos professores, especialmente redações de alunos e artigos de jornal e revista. Tais discussões foram intermeadas com relatos do contexto escolar.

A análise que se segue apresenta a perspectiva dos educadores respeitando as diferenças entre os dois momentos da pesquisa de campo: redações individuais e discussão grupal.

\section{Primeiras aproximações dos professores com a temática da Progressão Continuada no âmbito desta pesquisa}

Inicialmente, apresentaremos os elementos representativos da compreensão de professores acerca da Progressão Continuada presentes nas redações individuais que consistiram na primeira aproximação da pesquisadora com os professores. Tal análise foi dividida em três eixos: o que entendem por Progressão Continuada; como ela acontece na salade-aula e dificuldades encontradas em sua implantação.

\section{Como educadores compreendem a Progressão Continuada}

Apesar de algumas redações aproximarem-se do discurso oficial, a maioria diferia significativamente dele, demonstrando haver desconhecimento dos professores em relação ao projeto oficial ou ainda um distanciamento entre o discurso oficial e a Progressão Continuada construída nas escolas. Esse desconhecimento, em princípio, gerava constrangimento nos professores ao serem convidados a se manifestar.

Constatamos que a discrepância entre o discurso oficial e a concepção dos professores é mais forte na identificação da progressão continuada com a promoção automática, como é percebido nos seguintes trechos:

"No meu entender, significa promoção automática".

"No meu ponto de vista é a forma de promover um aluno de forma automática, retendo somente em situações específicas. Ex: faltas".

“... sistema implantado para o avanço dos discentes aos ciclos seguintes. Para isso é dividido em ciclos, há avanços anuais".

“Com a Progressão Continuada, existe uma alteração relativa à aprovação por séries e passa a ocorrer uma aprovação por ciclo".

De maneira geral, os professores participantes vivem a Progressão Continuada e pouco conhecem a seu respeito, reduzindo-a a dimensões referentes à promoção automática dos alunos. As redações demonstram a necessidade da ampliação de informações bem como da articulação do discurso oficial com a realidade escolar.

\footnotetext{
${ }^{3}$ Inspiramo-nos na Tese de Freitas, 2000.
} 
Como a Progressão Continuada acontece na sala de aula

Os professores indicaram que houve mudanças concretas no dia-a-dia escolar com a Progressão Continuada, mencionando, sobretudo, a avaliação. De maneira geral, a escola nesse novo regime é vista negativamente, suas críticas recaindo principalmente sobre a forma de implantação, bem como sobre as repercussões no alunado e na finalidade da escola.

Em relação à implementação, os professores consideram que houve pouca participação dos diversos segmentos da escola na discussão e nas estratégias dessa implementação, como podemos observar nos excertos das redações a seguir:

"Sinto-me desorientada. Simplesmente muda-se o método, mas não se o ensina aos professores! Parece-me que esse projeto foi simplesmente 'jogado' nas escolas e me sinto uma marionete que faz o que mandam e que deixa de agir por suas próprias conviç̧ões, até certo ponto, é claro".

"Nem mesmo a família estava preparada para uma mudança tão radical. Essa progressão seria válida se a criança recebesse orientação da importância de aprender para ter um futuro melhor e não apenas para ser aprovada".

Além disso, mencionam a falta de apoio à escola e aos docentes para tornar a política bem sucedida. Segundo uma professora, "precisaria ter vários respaldos para auxiliar o professor em suas dúvidas e com aqueles alunos que não estão interessados ou têm dificuldades".

Outro aspecto centra-se na mudança no processo de avaliação. Para os professores, a escola está, historicamente, centrada na nota enquanto instrumento de pressão para o estudo e a ausência desta produziria diminuição do aprendizado. A política ainda é criticada por implicar em menor cobrança sobre o aluno, o que repercutiria na falta de dedicação à escola.

"Não há necessidade de nenhuma cobrança (notas, provas etc.), sendo que o aluno deve por si só se interessar pelo que está sendo ensinado. Este método, embora muito bom na teoria, na prática não funciona, pois ninguém se esforça e se dedica a nada se não houver cobrança, disciplina e respeito".

Nas redações, as principais repercussões da Progressão Continuada focalizam o comportamento e aprendizado dos alunos. Segundo escreveram, houve aumento da indisciplina e da falta de interesse pelos conteúdos, representados no não-cumprimento das tarefas pelos alunos, tendo em vista a ausência de mecanismos de cobrança por parte do professor. Os trechos abaixo ilustram tais questões:

"A última coisa que eles querem é estudar, aprender, prestar atenção às explicações, participar das atividades e melhorar seus conhecimentos. $O$ que Ihes interessa mesmo é formar grupinhos, se divertir fazendo todos os tipos de bagunça e, melhor de tudo, ver o desespero do professor tentando inutilmente despertar o interesse e manter a disciplina em sala". "Há um fenômeno cada vez mais nítido, infelizmente, e mais constante: é a apatia; jovens que deveriam estar animados e com força, apenas comparecem à escola em busca da presença (o que é mais cobrado), mas sem vontade alguma de qualquer esforço. Passa a impressão, esse fenômeno, de que os alunos estão acostumando a ganhar tudo de maneira fácil".

"Os alunos não compreenderam o que é essa progressão, e, com isso, se acomodaram, não participando das aulas, não executando as tarefas propostas, pois, na opinião deles, participando ou não das aulas, com certeza irão para série seguinte. Por estes motivos, as salas estão ficando, a cada dia que passa, mais indisciplinadas".

$\mathrm{Na}$ perspectiva dos professores, a 'promoção automática' implica na perda de valor do saber e do aprender. Assim, os alunos acabam considerando a escola mais como espaço de lazer do que de produção de conhecimentos. A esse respeito dizem:

"Não há, por parte do aluno, nenhum compromisso com a aprendizagem. A escola tornou-se lugar de encontros e lazer". 
"Nesse parâmetro, o aluno vem na escola apenas para rever os amigos, brincar, conversar em classe, além de não respeitar o professor que fica ministrando aula para mais ou menos $10 \%$ da classe".

Os professores ressaltam uma mudança na finalidade da escola, afastando-se de seu papel de socialização do conhecimento historicamente acumulado (identificado com a cobrança advinda da nota) e assumindo primordialmente dimensões de convivência à medida que os instrumentos de avaliação se flexibilizaram.

\section{Dificuldades que os professores enfrentam com a} Progressão Continuada

Se os professores afirmam que o aluno só vai à escola para usufruir um espaço de socialização, o trabalho docente, em contrapartida, é visto com desmotivação, gerando um círculo vicioso na relação professor/aluno. Como conseqüência da menor cobrança sobre o aluno, comparece o aumento da exigência sobre o professor:

“... fica cada dia mais difícil para o professor aplicar os conteúdos, sendo obrigado a criar vários métodos e mesmo assim não obtendo resultado. Cada dia fica mais difícil transmitir o que sabemos e é necessário para o aluno".

Várias redações diziam que o aumento na dedicação docente parecia em vão, pois o rendimento dos alunos caiu e os problemas disciplinares aumentaram. Assim, falavam em queda no rendimento do próprio trabalho, visto como desgastante:

“...cada dia que passa está sendo mais difícil conseguir resultados bons e satisfatórios. Por mais que eu planeje aulas e atividades diferentes para despertar o interesse do aluno, parece que menos estou conseguindo, ou seja, os resultados estão cada vez mais insatisfatórios".
Ao escrever sobre a docência em tempos de Progressão Continuada, muitos professores focalizaram as queixas aos alunos, vistos, em sua maioria, negativamente:

"No meu trabalho em sala de aula, as condições de aproveitamento e disciplina pioraram consideravelmente, onde os grandes prejudicados são os alunos que vêm à escola em busca do saber".

Ao descreverem o trabalho nessa política como sendo maior e mais árduo, uma vez que enfrentam dificuldades para torná-lo bem sucedido (estas quase sempre colocadas nos alunos), os professores explicitaram algumas de suas angústias. Havia forte sentimento de desânimo e de desvalorização profissional: "Depois da Progressão Continuada, sinto que o meu trabalho perdeu o valor que tinha tempos atrás".

Além disso, muitos diziam estar perdidos quanto ao próprio papel, uma vez que não encontravam estratégias bem sucedidas para ensinar os alunos. Consideravam que o sentido da docência estava atrapalhado, confuso, bagunçado. Uma professora disse sentir-se "correndo atrás de nota para os alunos", que "perderam, em parte, essa preocupação". Tal estrutura teria mesmo abalado sua vontade de ensinar:

“...outra mudança seria na minha vontade, no meu entusiasmo; sinto-me desanimada um tanto, porque o trabalho do professor está cada vez mais complicado, ficando as nossas funções "bagunçadas”."

Se o trabalho é vivido como luta diária para vencer inúmeras dificuldades, houve quem falasse em desistência como 'estratégia de sobrevivência' profissional ${ }^{4}$ :

"Como conseqüência, tenho procurado me dedicar inteiramente àqueles que realmente querem aprender e têm consciência de que é muito importante o estudo e a cultura. Quanto aos outros, espero sinceramente que algum dia mude de idéia

${ }^{4}$ A "síndrome da desistência" ou "burnout" vem sendo estudada por Codo (I999) 
e se tornem mais responsáveis e gratos àqueles que os tentam ajudar".

Apesar dessas dificuldades, há professores que pensam diferentemente, falando do próprio trabalho como persistência e militância:

"Mesmo assim não desisto, quero lutar sempre, pois tenho certeza que mesmo não atingindo $100 \%$ dos meus alunos, pelo menos $10 \%$ consigo atingir e isto faz com que eu continue lutando para um dia chegar aos 100\%".

A partir de alguns elementos das redações, observamos que muitas questões reproduzem situações ou sentimentos presentes no início da implantação do Ciclo Básico. As temáticas da pouca participação docente na implementação desta política bem como dos critérios de promoção retornam aos discursos docentes, acrescidas das conseqüências nefastas tanto para professores quanto para alunos do pouco enfrentamento destas questões no dia-adia escolar.

Para um professor, uma dessas conseqüências estaria nas dificuldades que esta geração vai enfrentar por ser alijada do acesso ao conhecimento no processo de escolarização. Com isso, ele reitera o papel da escola na formação humana e nas condições de vida em uma sociedade de classes. Esta questão é abordada com tristeza e preocupação em sua redação e conclui afirmando: "Eles certamente irão aumentar as estatísticas dos desempregados".

Ao término de cada redação, os professores manifestaram a intenção de discutir com a pesquisadora a atual política educacional, solicitando um aprofundamento no conhecimento da legislação. Esse interesse foi, então, canalizado para a criação de um espaço grupal de discussão aproveitando o Horário de Trabalho Pedagógico Coletivo, instituído semanalmente.

\section{Pensando a Progressão Continuada coletivamente no pequeno grupo}

As discussões em pequenos grupos tiveram como objetivo problematizar os discursos produzidos nas redações a fim de melhor compreender as nuances da implementação da Progressão Continuada tendo como ponto de partida, a leitura coletiva do Parecer do Conselho. Sua relevância foi ratificada pela intensa participação dos docentes que traziam jornais, revistas e material de alunos para contribuir.

A análise a seguir centra-se em dois eixos: a implantação e as intenções oficiais, e relatos de experiências do novo contexto escolar.

\section{A implantação da Progressão Continuada e as intenções oficiais}

A partir da constatação de que os docentes pouco sabiam sobre o conteúdo oficial desta política, da qual são os principais protagonistas, deu-se início à leitura do documento oficial. À medida que as discussões grupais avançavam, os professores apresentavam uma avaliação positiva da proposta governamental, embora sempre acrescida de críticas, centradas sobretudo na forma como ela foi implantada.

Para uma professora, a Progressão Continuada possuía aspectos pedagógicos interessantes; no entanto, queixava-se da forma contraditória de implantação adotada pelo estado: embora a lei enfatizasse a importância da ampla discussão, tal discussão de fato não tinha ocorrido. Outro professor também argumentou nesse sentido, contraponto a implantação "autoritária" com a presença constante do termo "democracia" no projeto de lei: "o sentido de democracia é restrito".

Muitos professores destacaram a inexistência de esclarecimentos dos aspectos político-pedagógicos envolvidos nessa organização escolar. A pequena ou inexistente preparação provocou neles um sentimento de que a política foi imposta e sem a devida estrutura, como se nota na seguinte fala: "Foi jogado, planejado no papel e só. Até daria certo se houvesse preparação".

Talvez justamente por apostarem na sua viabilidade, os professores vislumbravam outras possibilidades de instituir essa política, mais cuidadas e respeitosas com aqueles que seriam seus agentes: escola, professores, alunos e famílias. Preocupavam-se, ainda, com o caráter pedagógico do projeto pensando em formas de garantir a qualidade do ensino no processo de implantação. 
Para uma professora, inicialmente seria necessário preparar a escola, referindo-se ao espaço físico e à orientação dos agentes escolares. Além disso, entendia que uma mudança desse porte necessitava de tempo, e portanto não poderia ter sido implementada em toda rede de uma única vez. Ao contrário, deveriam tê-la instituído gradativamente: inicialmente na primeira série, acrescentando uma série a cada ano, até atingir a $8^{a}$ (depois, portanto, de oito anos). Para ela, a implantação 'continuada' (nome usado em alusão à política) possibilitaria o maior acompanhamento dos alunos, especialmente porque eles teriam toda a trajetória escolar no interior dessa lógica.

A partir da leitura do parecer oficial, a compreensão desta política foi sendo ampliada, ao mesmo tempo em que confrontada com a realidade escolar. Uma das tônicas da discussão era a idéia de que "o projeto é lindo no papel", "a intenção podia até ser boa, mas a realidade é outra". Assim, o texto oficial, quando colocado frente a frente com o discurso docente, parecia não corresponder à realidade escolar: "a lei é muito bonita, mas não dá, porque estamos falando de alunos que não sabem nada".

Convivendo com essa visão, havia outra, bastante marcante, que a contradizia: era a concepção de que o projeto "não é tão lindo no papel". Ou seja, críticas ao projeto sempre compareciam retirando o brilho do mesmo. Dentre as críticas, uma bastante enfatizada refere-se à questão econômica, considerada por diferentes docentes como "sentido oculto" da política educacional.

Quando o documento oficial explicitou essa questão, os comentários generalizaram-se. Um professor disse que o objetivo "não parecia ser resolver o problema da reprovação, mas eliminá-lo”. Para outra, nem sempre a inteção é boa: "A intenção é tirar os repetentes da escola e diminuir a evasão para receber verbas do exterior". Outro professor, destacando que para o Estado "reprovação é desperdício", emendou que não havia preocupação com a formação dos alunos: "É conversa para boi dormir. É para inglês ver... Ou melhor, para americano ver, porque quem paga é o $B I R D$, são os americanos". Uma professora foi contundente: "Ah, bom! É mais barato... 'Vocês reprovam muito, como querem ganhar bem?'. Então, o negócio é aprovar todo mundo, para ganhar melhor". Ironizou, assim, o trecho que dizia que com a Progressão Continuada, o salário docente poderia aumentar, pois "não sentira tal aumento salarial".

Outras temáticas do documento foram discutidas pelos professores no decorrer da leitura grupal. Aspectos da prática docente, alterados no novo contexto, foram abordados tanto em seus pontos positivos quanto negativos, de forma a re-significar a compreensão da Progressão Continuada. Temas como reprovação, avaliação, reforço, freqüência, rendimento e comportamento dos alunos e trabalho docente foram analisados pelo grupo que teceu críticas à própria prática e ao mesmo tempo questionou os limites da atual política.

\section{Como a política de Progressão Continuada acontece} na sala de aula

Um aspecto amplamente discutido no grupo foi reprovação, quando os professores não apenas relataram como ela se dava antes da Progressão Continuada, mas também comentaram como ela vinha funcionando no interior do novo regime.

De maneira geral, eles concordavam que antes, os índices de reprovação eram altos, e que algo deveria ser feito para alterar a situação. Para uma professora, não havia sentido em reprovar por "meio ponto na média". Outra professora afirmou que "tinha alunos há cinco anos na $5^{a}$ série", e se era consensual que a retenção precisava ser repensada e transformada, a solução adotada pelo Estado passava longe do consenso. As discussões tenderam para a opinião segundo a qual a Progressão Continuada substituiu "uma distorção por outra", ou seja, para mudar o alto índice de reprovações, eliminou-se a possibilidade de o professor reter seus alunos. A frase "da pedagogia da repetência à pedagogia da enganação" foi uníssona. Para os professores, a exclusão no interior da escola permaneceu com a Progressão Continuada, porém de maneira mais sutil e por isso agravada.

Atrelada à discussão sobre reprovação vinha a queixa acerca da "promoção automática". Nas redações, os termos progressão, promoção automática, continuada assumiram diversas combinações: "progressão automática”, "promoção continuada", 
"promoção automática", a oficial "progressão continuada". Estas combinações não são apenas possibilidades semânticas, mas revelam a pouca clareza que se tem, ou a pouca diferença que se vê entre tais conceitos.

Todos os professores falavam, com angústia, da pressão vivida para aprovar "a qualquer custo". Uma professora relatou que a retenção estava sendo coibida antes mesmo de instituir-se a Progressão Continuada: "Antes, a gente era pressionado a dar um jeitinho de ver o progresso do aluno. Então, para disfarçar, não ficar tão forçado, criaram a Progressão Continuada".

Quando o debate girou em torno de alunos defasados que, no interior dos ciclos, passaram a serem aprovados compulsoriamente, uma professora ressaltou que não se tratava de "aprendizagem num passe de mágica", mas apenas de novos números educacionais. Para outra professora, alguns alunos, apesar de oficialmente aprovados, não tinham, na prática, condições de acompanhar suas turmas: "é isso que provoca a exclusão". Alguns professores apontaram que esta política educacional centra-se mais no intento de agilizar a passagem do aluno pela escola e não de garantir a permanência e aprendizagem. A nivelação pela faixa etária se sobrepõe a outros critérios.

Diante deste contexto, a avaliação torna-se tema central. Um professor destacou que a política tinha como centro a mudança no processo de avaliação do aluno, portanto, este precisaria ser bem cuidado, caso contrário, a política tenderia ao fracasso. Eles concordavam que a avaliação precisava ser repensada, pois apenas uma prova não avalia plenamente o aproveitamento escolar: "às vezes o aluno não está bem e vai mal". Porém, entre a necessidade de repensar a avaliação e a experiência concreta na Progressão Continuada havia dissenso: "a avaliação é só para termos certeza de que o aluno não aprendeu nada, porque a gente não pode retê-lo".

Muitos professores relataram ter mudado sua forma de avaliar os alunos. Tal mudança, no entanto, era vivida de maneira angustiada. Um professor afirmou: "Eu anoto as atividades que os alunos fazem em classe, comportamento, se atrapalha ou não; realizo avaliações com e sem consulta. Mas tem aluno que não dá.... E depois a gente vai passá-lo...”. Outra professora, concordando, disse: "Eu já caí na real. Nesse bimestre, só prova com consulta".

O reforço escolar também foi discutido, tanto em seu caráter abstrato quanto na experiência concreta vivida no novo regime. Para uma professora, "os alunos tinham que ter aulas extras para acompanhar o ritmo da série certa", o que não estava acontecendo. Outra professora concordava com a necessidade de reforço, mas tinha críticas à forma como ele estava sendo realizado: "o reforço não é adequado; a recuperação de janeiro está errada. Se os alunos tivessem mesmo que assistir aula nas férias, não pensariam duas vezes".

$\mathrm{Na}$ escola da Progressão Continuada, a avaliação e - reforço foram modificados, não possuindo papel classificatório. A possibilidade de reter os alunos, então, centra-se no controle da freqüência que passou a assumir o papel que antes competia à avaliação. A punição e a premiação permanecem nas escolas, mas agora envolvem a presença. De fato, muitos mencionaram a freqüência como única forma de controle da classe: "o que conta mesmo é a presença, ou melhor, a falta".

Tema presente em vários encontros foi a repercussão da ausência de reprovação no rendimento e no comportamento dos alunos. Os professores, de modo geral, enfatizaram que depois dos ciclos, a indisciplina aumentou, pois o aluno sabe que não será mais punido. Vários professores relataram que os próprios alunos pediam limites claros. Enraizada entre os professores estava a crença de que "o ser humano só funciona na mentalidade da cobrança".

Ligado a esta questão encontra-se o (des)valor do conhecimento. De maneira geral, os professores entendiam que a queda do valor do conhecimento era produzida por diversos fatores interligados: a promoção automática dos alunos, a escolarização centrada apenas na freqüência e a avaliação assumindo papel de constatação da situação escolar, e não de instrumento decisivo do futuro do aluno. No depoimento dos professores, a facilidade para 'passar de ano' teria gerado desestímulo inclusive em alunos que, antes, eram esforçados. Tais alunos teriam perdido a vontade de aprender, sentindo-se injustiçados, pois não havia conseqüências para os que não se esforçassem. Para eles, a conseqüência de uma 
política na qual "os maus alunos são valorizados e os bons alunos, desconsiderados" era o empobrecimento da educação.

Além das queixas acerca dos alunos desinteressados e da angústia pela desvalorização dos esforçados, havia ainda uma modalidade de aluno que suscitava outro tipo de angústia. Trata-se daqueles que, muito embora avançassem pelos anos escolares, traziam consigo uma defasagem entre a série em que se encontravam e o conhecimento que levavam consigo. Para ilustrar a situação, os professores traziam trabalhos de alunos, dentre os quais, a seguinte redação de uma aluna de $7^{\text {a }}$ série:

"O natal e uma selebrasão do nacimento de jesus que ser dounor um feriado que doda a familia se reune mais os amigos e vais uma sei de natal que damos presendes e gaiamos presendes istoramos japaem damos pregamo conversamos. $E$ adoro o natal e muito bom o natal selepamas o namento de jesus e fasemos festas. Mais dem mais coisas soutamos, asedemos a missa. E muito bom. Mais que eu me esquesa dambem dem o vamoso papai noel um velhilho que trais presente para todas griansas".

Essa redação passou pelas mãos dos professores, produzindo comentários carregados de choque e desolação. Uma professora exclamou incisivamente: "no momento em que a escolaridade for chamada, ela vai se sentir uma inútil e vai-se perguntar 'o que eu tenho?'. Essa é a verdadeira discriminação".

Finalmente, foi retomado no âmbito do grupo um aspecto presente nas redações: a queixa em relação ao próprio trabalho. Se muitos alunos não conseguiam aprender, e a maioria estava desestimulada em relação à escola, também os professores sentiam-se sem estímulo. A relação desestímulo discente-desestímulo docente parecia ter-se tornado um círculo vicioso difícil de quebrar.

A coordenadora pedagógica, algumas vezes, defendeu que eles deveriam pensar em uma nova forma de trabalho com os alunos que mostrasse a importância de aprender, dando-lhes uma perspectiva de futuro. Ao mesmo tempo, dizia não saber exatamente como fazer isso. De modo geral, não viam outra maneira que a nota, a reprovação, a cobrança. Sentiam-se desorientados.

Alguns professores disseram que, recebendo um salário baixo (desestimulante) e não encontrando, na sala de aula, estímulos para o trabalho não preparavam mais as aulas com cuidado, também se despreocupando dos conteúdos. A vontade de ensinar parecia abalada. Havia, para eles, uma inversão de valores vivida com sofrimento.

Quando pensavam acerca do que estaria produzindo desestímulo, demonstravam-se confusos, apresentando razões ora intrapsíquicas, ora de ordem política e institucional. Uma professora relatou que seu dia-a-dia profissional estava difícil, pois não estava mais empolgada como antes. Embora destacasse que a falta de interesse dos alunos a "contagiava", por vezes dizia não saber o que a fazia sentir-se tão desestimulada (se era algum problema pessoal ou mais geral). Tal dúvida era vivida por ela com estranheza, pois desde que começara a dar aula, "nunca havia sido como agora". Em um dos encontros, essa mesma professora desabafou: "estou deixando de ser uma professora digna. Não importa o que eu faça, o aluno passa. Não vale nada o nosso trabalho". Outra professora também foi contundente ao enfatizar que o sentimento que mais a tocava, quando em relação ao trabalho, era a "vergonha". Sentia, ainda, que o professor, cada vez mais, era peça "dispensável” da escola.

\section{Considerações Finais}

Neste artigo, destacamos que a Progressão Continuada deve ser entendida como estratégia de enfrentamento dos altos índices de reprovação e evasão escolares que vem sendo gestada historicamente no estado de São Paulo, tendo como importante marco a implantação do Ciclo Básico.

Tal proposta tomou consistência ao longo das duas últimas décadas, sendo atualmente adotada em várias redes públicas de ensino brasileiras (Silva, 1997). Análises recentes a respeito da organização do ensino em ciclos em diferentes estados e municípios do Brasil (Mainardes, 1998; Barreto \& Mitrulis, 200I; Barreto 
\& Sousa, 2004) permite-nos verificar que, embora com princípios comuns, há diferenças significativas, especialmente quanto aos motivos da implantação, à duração de cada ciclo, às formas de avaliação e à maneira de implementá-los. Essa diversidade é fruto de diferentes gestões político-administrativas que ora se aproximam de práticas mais democráticas, ora de práticas centralizadas nos gestores dessas políticas. Tais diferenças têm repercussões nas concepções e práticas de professores na sala de aula imprimindo marcas no maior ou menor êxito dessas reformas educacionais.

Maldonado (2002) chama a atenção para o fato de que os professores, em sua trajetória, vão construindo saberes tanto em relação à prática docente como também em relação aos programas de governo, implantados sucessivamente no sistema escolar. Nesse sentido, suas análises revelam dimensões importantes que não podem ser desconsideradas na constituição de políticas públicas em educação.

Por esse motivo, procuramos formas de aproximação com educadores visando apreender como compreendem e vivenciam a Progressão Continuada. Nesta pesquisa, constituímos estratégias de aproximação com professores objetivando aprofundar as concepções que possuem a respeito desta nova política educacional, o que foi feito por meio de escrita de redações e discussão em pequenos grupos de professores de uma escola pública estadual paulista.

Com vistas a sintetizar alguns aspectos presentes na pesquisa, consideramos que: a) os docentes, de maneira geral, desconhecem a proposta oficial da progressão continuada, tendo, vários deles afirmado que, por intermédio do trabalho em grupo com a pesquisadora, eles tiveram o primeiro contato com os documentos oficiais; b) ao falarem dessa proposta, muitos a denominavam de "promoção automática", considerando que, embora esta prometa enfrentar a questão da reprovação, acabou por eliminá-la por decreto; c) ao conhecerem os documentos oficiais, analisaram a Progressão Continuada sob duas vertentes: a primeira é que, se esta proposta políticopedagógica é interessante, por reduzir a repetência, a contrapartida é exigir que se repense toda a organização escolar; a outra vertente é que tal programa de governo não enfrenta ou não explicita como enfrentar a cronicidade de problemas presentes na escola pública, especialmente no que se refere aos baixos salários docentes, à desmotivação de alunos e professores e às más condições de trabalho. Com isso, a Progressão Continuada apenas aprofunda a desigualdade social, por não dar melhores condições aos alunos que nela ingressam em uma situação já socialmente desigual.

O desconhecimento da proposta oficial por parte dos professores, visível desde nosso primeiro contato com a escola, está presente em outros estudos do tema (Freitas, 2000; Guimarães, 200I; Arcas, 2003; Bertagna, 2003). Freitas (Op. Cit.) também destaca a gravidade da situação ao pontuar que o sistema de ensino paulista tem sofrido com a avalanche de políticas educacionais presentes na escola, o que vem no sentido muito mais de provocar rupturas e desarticulações do que de contribuir com a superação de seus problemas históricos.

Assim, tal desconhecimento parece ser revelador da ausência de possibilidade de participação dos professores na construção dessa política educacional, constatação que se contrapõe à suposição de desinteresse docente a mudanças de grande porte. Assim, a oportunidade de ter acesso a documentos oficiais, bem como de discutir a proposta governamental à luz de suas práticas educativas, fez sentido aos professores acompanhados na presente pesquisa, revelando que é possível fazer na escola uma discussão da lei que não seja burocrática.

Para tanto, é fundamental que aqueles que se proponham a fazer uma discussão como essa, entendam as críticas docentes não como mera "resistência" à intenção proclamada oficialmente, mas como parte de sua compreensão frente à complexidade da realidade escolar. Ora, a discussão sobre a Progressão Continuada no grupo reflexivo aponta que os professores estavam sensíveis à necessidade de mudança da escola, tendo em vista sua finalidade formadora. Assim, havia consenso em torno da importância de se repensar o processo avaliativo bem como de elaborar estratégias para enfrentar $\circ$ alto índice de reprovação e envolver os 
alunos em uma aprendizagem significativa, princípios defendidos também pelo discurso oficial ${ }^{5}$.

Mas se os professores e o poder público concordavam com a necessidade de enfrentamento dos altos índices de reprovação e evasão existentes na escola pública, havia entre eles pontos de dissenso. Especial destaque deve ser dado à discordância quanto à forma de elaboração e implantação deste projeto educacional, na qual os professores pouco puderam participar. Tal crítica retoma questionamentos feitos pela rede escolar relativos à implantação do Ciclo Básico acrescidos de uma dimensão presente na década de 80 , mas que não se realizou ao final dos anos 90, a saber: a existência de programas de formação sobre os princípios da proposta no momento de sua implantação. Criticavam, também, a ênfase na motivação econômica e não pedagógica dos projetos pedagógicos.

A partir da análise das concepções dos professores, pode-se afirmar que criticar a Progressão Continuada não é ser favorável à reprovação e à exclusão, mas ter em vista que o acesso e a permanência do aluno na escola não podem prescindir da qualidade do ensino oferecido. Muitas de suas críticas recaíam na perda progressiva da apropriação do conhecimento pelos alunos. Questionavam que a escola hoje acaba cumprindo muito mais uma função socializadora do que de ensino/aprendizagem.

No entanto, apesar da preocupação com a qualidade do ensino, permanece no discurso docente uma visão de que o aluno da escola pública tem poucas condições ou dificuldades de aprendizagem, o que contradiz, em essência, o propalado caráter democrático desse programa de governo. Se a progressão continuada foi bem sucedida no campo das estatísticas de reprovação, esta não superou a hegemonia da visão negativa quanto ao alunado, sendo apontada como um dos importantes fatores na produção da reprovação escolar ao menos desde a década de 1980 (Patto, 1990). Vale, portanto, destacar que se trata de uma visão presente não apenas no discurso dos professores, mas legitimada no próprio discurso oficial.
A essa visão pejorativa dos alunos, alia-se um processo de avaliação imposto pela proposta governamental, considerado pelos professores como permissivo, insuficiente e ineficiente. Isso tem repercussões práticas, desveladas na existência de alunos que, embora galguem os anos escolares mais altos, não têm condições de ler e interpretar um texto simples ou fazer as quatro operações matemáticas. Portanto, mesmo sendo proibida a reprovação, a exclusão na escola se manteve intocada.

Nesse sentido, podemos considerar que o sucesso de políticas educacionais do porte do regime de Progressão Continuada, ou seja, que visam mudanças "radicais e profundas", depende da adesão de professores, que devem se engajar na sua construção diária no interior da escola. No entanto, cabe aos gestores que tenham o ideal de democratizar o ensino público, pensar em meios de democratizar a própria implementação de políticas públicas, aproximando-se do consenso de forma participativa, ampla e irrestrita. Caso contrário, seus projetos correm o risco permanente de serem transformados em mais um programa de governo, que mesmo bem intencionado, encontra-se à mercê dos desigínios de outros gestores.

\section{Referências}

Almeida Junior, A. (1957). Repetência ou Promoção Automática? Revista Brasileira de Estudos Pedagógicos, 27(65), 3-15.

André, M. E. D. A., \& Lüdke, M. (1986). Pesquisa em Educação: Abordagens Qualitativas. São Paulo: EPU.

Arcas, P. H. (2003). Avaliação da aprendizagem no regime de progressão continuada: o que dizem os alunos. Dissertação de Mestrado, Faculdade de Educação, Universidade de São Paulo, São Paulo.

Barreto, E. S., \& Mitrulis, E. (200I). Trajetórias e desafios dos ciclos escolares no País. Estudos Avançados, 15(42), I03140.

\footnotetext{
${ }^{5}$ Ao estudar a avaliação da aprendizagem no regime de Progressão Continuada, Arcas (2003) revela a existência dessa mesma situação na escola por ele pesquisada.
} 
Barreto, E. S., \& Sousa, S. Z. (2004). Estudos sobre Ciclos e progressão escolar no Brasil: uma revisão. Educação e Pesquisa, 30(I), 3I-50.

Beisiegel, C. R. (198I). Relações entre a quantidade e a qualidade no ensino comum. Revista ANDE, I(I), 4I-56.

Bertagna, R. H. (2003). Progressão continuada: limites e possibilidades. Tese de Doutorado, Faculdade de Educação, Universidade Estadual de Campinas, Campinas.

Brasil. (1996). Ministério de Educação e Cultura. Desenvolvimento da Educação no Brasil. Brasília.

Conselho Estadual de Educação. (1997a). Parecer CEE Nº 8/ 97. Regime de progressão continuada. Legislação do Ensino de Fundamental e Médio. (pp. I50-155). São Paulo.

Conselho Estadual de Educação. (1997b). Indicação CEE N ${ }^{\circ}$ 22/97. Avaliação e progressão continuada. Legislação do Ensino de Fundamental e Médio. (pp. 254-257). São Paulo.

Codo, W. (Org). (1999). Educação: carinho e trabalho. Petrópolis, RJ: Vozes/CNTE, Universidade de Brasília.

Dechichi, C. (200I). Transformando o ambiente da sala de aula em um contexto promotor do desenvolvimento do aluno deficiente mental. Tese de Doutorado, Pontifícia Universidade Católica de São Paulo, São Paulo.

Esposito, Y. L. (1985). A implantação do ciclo básico nas escolas estaduais de São Paulo: avaliação do primeiro ano. São Paulo: Secretaria da Educação.

Ezpeleta, J., \& Rockwell, E. (I 986). Pesquisa participante. São Paulo: Cortez.

Ferrari, A. R. (1985). Analfabetismo no Brasil: tendência secular e avanços recentes - resultados preliminares. Cadernos de Pesquisa, 52, 35-49.

Ferraro, A. R. (1999). Diagnóstico da escolarização no Brasil. Revista Brasileira de Educação - ANPEd, 12, 22-47.

Freitas, J. C. (2000). Cultura e currículo: uma relação negada na política do sistema de Progressão continuada no estado de São Paulo. Tese de Doutorado, Pontifícia Universidade Católica de São Paulo, São Paulo.
Guimarães, M. N. N. (200I). Práticas pedagógicas em época de progressão continuada: um olhar sobre a avaliação. Dissertação de Mestrado, Universidade Federal de São Carlos, São Carlos.

Kubitschek, J. (1957). Reforma do Ensino Primário com base no sistema de Promoção Automática. Revista Brasileira de Estudos Pedagógicos, 27(65), I4I-I 45.

Leite, D. M. (1999). Promoção automática e adequação do currículo ao desenvolvimento do aluno. Revista Brasileira de Estudos Pedagógicos, 32, (75), 189-203.

Mainardes, J. (1998). A promoção automática em questão: argumentos, implicações e possibilidades. Revista Brasileira de Estudos Pedagógicos, 79 (192), 16-29.

Maldonado, R. M. (2002). Los saberes docentes como construcción social. México: Fondo de Cultura Econômica.

Patto, M. H. S. (1990). A produção do fracasso escolar: histórias de submissão e rebeldia. São Paulo: T. A. Queiroz.

Ribeiro, S. A. (199I). Educação e a inserção do Brasil na modernidade. Cadernos de Pesquisa, 84, 3-96.

Sampaio Dória, A. (19|8). Contra o analphabetismo. Anuário do ensino do estado de São Paulo. São Paulo.

Saviani, D. (1986). Escola e Democracia. São Paulo: Cortez e Editores Associados.

São Paulo. (1969). Secretaria do Estado da Educação. Departamento de Educação, Chefia do ensino primário. Programa da escola primária do estado de São Paulo. São Paulo.

São Paulo. (1987). Secretaria do Estado da Educação. Coordenadoria de Estudos e Normas Pedagógicas. Ciclo Básico. São Paulo.

Silva, A. (1997). São Paulo adota dois ciclos sem reprovação. Nova Escola On-line: Política Educacional, novembro de 1997.

Recebido em: 14/12/2005

Revisado em: 09/07/2006

Aprovado em: 14/10/2006 
Sobre as autoras

Lygia de Sousa Viégas (lyoviegas@uol.com.br) é mestre em Psicologia Escolar e do Desenvolvimento Humano e doutoranda no Programa de PósGraduação em Psicologia Escolar e do Desenvolvimento Humano do Instituto de Psicologia da Universidade de São Paulo.

Marilene Proença Rebello de Souza (mprdsouz@usp.br) é doutora em Psicologia e Professora do Instituto de Psicologia da Universidade de São Paulo.

Endereço para correspondência

Marilene Proença Rebello de Souza

Av. Professor Mello Moraes, 1721. Cidade Universitária

5508-900 São Paulo, SP 